\title{
The AGeS2 (Awards for Geochronology Student research 2) Program: Supporting Community Geochronology Needs and Interdisciplinary Science
}

\author{
Rebecca M. Flowers, Dept. of Geological Sciences, University of Colorado Boulder, Boulder, Colorado 80309, USA; J Ramón Arrowsmith, \\ Arizona State University, School of Earth \& Space Exploration, Tempe, Arizona 85287, USA; Vicki McConnell, Geological Society of \\ America, 3300 Penrose Place, Boulder, Colorado 80301, USA; James R. Metcalf, Dept. of Geological Sciences, University of Colorado \\ Boulder, Boulder, Colorado 80309, USA; Tammy Rittenour, Dept. of Geology, Utah State University, Logan, Utah 84322, USA; and \\ Blair Schoene, Dept. of Geosciences, Princeton University, Princeton, New Jersey 08544, USA
}

\section{THE INCREASING \\ GEOCHRONOLOGY DATA AND \\ EDUCATION NEEDS OF THE EARTH-SCIENCE COMMUNITY}

Geochronology is essential in the geosciences. It is used to resolve the durations and rates of earth processes, as well as test causative relationships among events. Such data are increasingly required to conduct cutting-edge, transformative, earth-science research. The growing need for geochronology is accompanied by strong demand to enhance the ability of labs to meet this pressure and to increase community awareness of how these data are produced and interpreted. For example, a 2015 National Science Foundation (NSF) report on opportunities and challenges for U.S. geochronology research noted: "While there has never been a time when users have had greater access to geochronologic data, they remain, by and large, dissatisfied with the available style/ quantity/cost/efficiency" (Harrison et al., 2015, p. 1). And the 2012 National Research Council NROES (New Research Opportunities in the Earth Sciences) report (Lay et al., 2012, p. 82) recommended: "[NSF] EAR should explore new mechanisms for geochronology laboratories that will service the geochronology requirements of the broad suite of research opportunities while sustaining technical advances in methodologies." The AGeS (Awards for Geochronology Student research) program is one way that these calls are being answered.
THE AGeS1 PROGRAM: A COLLABORATIVE STRATEGY FOR SUPPORTING COMMUNITY GEOCHRONOLOGY NEEDS

The AGeS program is a collaborative strategy for supporting access to geochronology data and expertise. The goals of AGeS are to (1) broaden access to geochronology; (2) educate users of geochronology data; (3) promote synergistic science by fostering new relationships between labs, students, and scientists in different disciplines; and (4) provide strategic, high-quality, scientifically valuable geochronology data for projects in which both users and producers of the data are intellectually engaged. The AGeS program offers support of up to US $\$ 10,000$ (typical awards $\sim$ US\$8,500) for graduate students to visit an AGeS lab for a week or more, participate in sample preparation and analysis, and learn fundamental aspects of the methods, techniques, theory, and interpretational approaches used in modern analytical facilities while being mentored by geochronologists on a project of joint interest. These awards fill an important funding gap between small (US\$1,000-US\$3,000) student research grant opportunities (e.g., Geological Society of America [GSA] student research grants) and large (>US\$100,000) NSF grants, and can be sufficient to acquire a publishable data set, catalyze new collaborations, and provide the foundation for future larger proposals.

AGeS1 was implemented in 2014 within the framework of the NSF EarthScope program (Flowers et al., 2014; Nadin, 2015). Twenty-five graduate students were engaged deeply in AGeS1 by receiving awards of US\$5,300 to US\$9,500 in 2015, 2016, and 2017 (Fig. 1A). The awards also financed "riskier" science ideas, some of which came to fruition (e.g., Williams et al., 2017). However, the impact of AGeS1 extends far beyond the funded projects. The AGeS1 funding opportunity provided a specific reason for geochronology users to reach out to the data producers annually, amounting to $>40-50$ contacts each year between students and labs regarding potential collaborative, interdisciplinary research projects. A total of 135 AGeS1 proposals including a diversity of geochronology techniques were submitted over three proposal cycles, each one involving new interactions between labs and students. Even for some unfunded projects, new research proceeded because the proposalwriting process helped focus and articulate the ideas and generated joint enthusiasm for the study. Six geochronology experts (scientists from private and state universities, a small liberal arts college, and a federal agency) dedicated substantial time to reviewing and ranking every submitted proposal, such that all students received feedback on their project ideas.

Between 2014 and 2018, the AGeS lab network grew to include 73 senior scientists associated with 43 labs distributed across the U.S., encompassing a wide range of geochronology methods (Figs. $1 \mathrm{~B}$ and $1 \mathrm{C})$. Any lab in the U.S. or its 

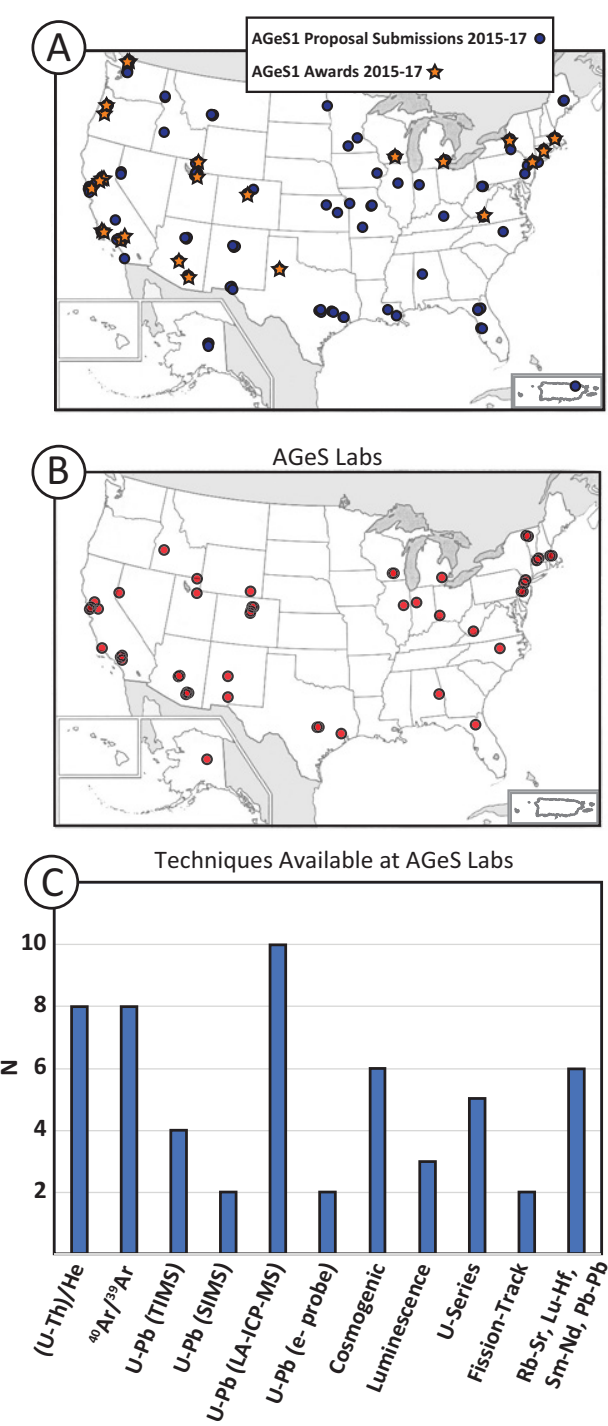

Figure 1. (A) Map showing locations of home institutions of the 135 submitted student proposals over three AGeS (Awards for Geochronology Student research) proposal cycles, along with the funded projects. (B) Map showing locations of the 43 AGeS geochronology labs. (C) Plot of techniques available at AGeS labs. LA-ICP-MS-laser ablation-inductively coupled plasma-mass spectrometry; SIMSsecondary ion mass spectrometry; TIMSthermal ionization mass spectrometry.

territories can become an AGeS lab by providing a one- to two-page lab profile that is posted on the AGeS lab database webpage (http://www.geosociety.org/ GSA/grants/ages2/labs.aspx) to help geochronology users connect with potential host facilities. The lab database only includes facilities that have self-identified as being interested in new collaborations. The lab profiles offer details about analytical costs, sample preparation, realistic time-frames for lab visits, and the education and training experiences provided for visitors. This wealth of information about labs enhances lab accessibility, makes the geochronologists behind the facilities more approachable to the greater user community, and serves as an unprecedented resource for scientists interested in using geochronology regardless of their relationship to the grant program.

\section{THE AGeS2 PROGRAM: \\ AN EXPANDED INITIATIVE}

Motivated by widespread support for AGeS1, new cross-programmatic funding from NSF has now built AGeS2 into a wider initiative. AGeS2 expands its purview beyond the primarily North American-based focus of the EarthScope AGeS1 program, to encompass the broader science supported by the Division of Earth Sciences of NSF, which aims at "...improving the understanding of the structure, composition, and evolution of the Earth, the life it supports, and the processes that govern the formation and behavior of the Earth's materials" (NSFGEO website). AGeS2 has double the annual award funding of AGeS1, and thus expects to support a total of 54-60 graduate student geochronology projects (18-20 per year) over three award cycles in 2019, 2020, and 2021. The outcome will be a broader suite of users, AGeS labs, and types of science that receive funding. A new partnership with GSA is enabling successful management of this effort.

AGeS2 will also take advantage of new opportunities for cohort- and communitybuilding afforded by the program's popularity to maximize the educational and scientific outcomes of AGeS investments. These activities will include regular teleconferences with each year's AGeS student cohorts and AGeS cohort gatherings prior to the 2020 and 2021 GSA Annual Meetings. Ongoing student-labadvisor interactions will be encouraged throughout the typical two-year AGeS project duration to further promote project success and publication productivity. We recognize the value of these sustained relationships and expect to characterize their quality and the networks that develop as part of our assessment effort.
For more information about $\mathrm{AGeS} 2$, go to www.geosociety.org/ages. As in AGeS1, interested students apply to AGeS2 by first initiating contact with an AGeS lab to discuss a potential project. If the lab feels that the proposed work is mutually beneficial, the lab helps the student refine and clarify the project. Students apply by submitting a project description and detailed budget with justification. Letters of support from the home institution project supervisor and host lab director complete the application.

\section{ACKNOWLEDGMENTS}

AGeS2 is supported by NSF EAR-1759200, -1759353, and -1759201 awards to R.M. Flowers, JR. Arrowsmith, and V. McConnell. AGeS1 was supported by NSF EAR-1358514, -1358554,

-1358401 , and -1358443 awards to R.M. Flowers, JR. Arrowsmith, T. Rittenour, B. Schoene, and J.R. Metcalf. We thank the AGeS1 review panel for their time invested in the proposal evaluation process.

\section{REFERENCES CITED}

Flowers, R.M., Arrowsmith, R., Metcalf, J.R. Rittenour, T., and Schoene, B.S., 2014, New EarthScope geochronology graduate student research and training program: inSights: The EarthScope Newsletter, Fall, p. 3.

Harrison, T.M., Baldwin, S.L., Caffee, M., Gehrels, G.E., Schoene, B., Shuster, D.L., and Singer, B.S., 2015, It's about time: Opportunities and challenges for U.S. geochronology: Institute of Geophysics and Planetary Physics Publication 6539, University of California, Los Angeles, 56 p.

Lay, T.H., Bender, M.L., Carbotte, S., Farley, K.A., Larson, K.M., Lyons, T., Manga, M. Mao, H.-K., Montanez, I.P., Montgomery, D.R., Olsen, P.E., Wiberg, P.L., Zhang, D., Lange, M., Ortego, J.R., and Gibbs, C.R., 2012, New Research Opportunities in the Earth Sciences: National Research Council, National Academies Press, 117 p.

Nadin, E.S., 2015, Good Times, Better Ages, How the EarthScope AGeS program evolved: inSights: The EarthScope Newsletter, Winter 2015-16, p. 3-4.

National Science Foundation (NSF-GEO), 2017 About Earth Sciences: www.nsf.gov/geo/ear/ about.jsp (accessed 29 Mar. 2017)

Williams, R.T., Goodwin, L.B., Sharp, W.D., and Mozley, P.S., 2017, A 400,000-year record of earthquake frequency for an intraplate fault: Proceedings of the National Academy of Sciences of the United States of America, v. 114 , no. 19 , p. $4893-4898$, https://doi.org/ $10.1073 /$ pnas. 1617945114 .

Manuscript Received 17 OCt. 2018 MANUSCRIPT ACCEPTED 20 Nov. 2018 